\title{
Morphological Characteristics of Eroded Plaques with Noncritical Coronary Stenosis: An Optical Coherence Tomography Study
}

\author{
Chao Fang, Jia Lu, Shaotao Zhang, Jifei Wang, Yidan Wang, Lulu Li, Yini Wang, Senqing Jiang, \\ Yanwei Yin, Junchen Guo, Fangmeng Lei, Huai Yu, Guo Wei, Yuan Yao, Tao Chen, Xuefeng Ren, Lei Xing, \\ Yingfeng Tu, Jingbo Hou, Jiannan Dai and Bo Yu
}

Bo Yu and Jiannan Dai are joint senior authors.

Department of Cardiology, The 2nd Affiliated Hospital of Harbin Medical University; The Key Laboratory of Myocardial Ischemia, Chinese Ministry of Education, Harbin, China.

Aims: Recent studies suggested plaque erosion with noncritical stenosis could be treated distinctly from that with critical stenosis, but their morphological features remained largely unknown. The present study aimed to investigate morphological features of eroded plaques with different lumen stenosis using optical coherence tomography (OCT).

Methods: A total of 348 ST-segment elevated myocardial infarction patients with culprit OCT-defined plaque erosion (OCT-erosion) were analyzed. Based on the severity of lumen area stenosis, all patients with OCTerosions were divided into the following three groups: Group A (area stenosis $<50 \%, n=50)$; Group B $(50 \% \leq$ area stenosis $<75 \%, n=146$ ); Group C (area stenosis $\geq 75 \%, n=152$ ).

Results: Compared with patients in Groups A and B, patients in Group C were older $(p=0.008)$ and had higher prevalence of hypertension $(p=0.029)$. Angiographic analysis showed that $72.0 \%$ of the eroded plaques in Group A were located in the left anterior descending artery, followed by $67.8 \%$ in Group B, and $53.9 \%$ in Group C $(p=0.039)$. OCT analysis showed that Group A had the highest prevalence of fibrous plaques $(p<0.001)$ and nearby bifurcation $(p=0.036)$, but the lowest prevalence of lipid-rich plaques $(p<0.001)$, macrophage accumulation $(p<0.001)$, microvessels $(p=0.009)$, cholesterol crystals $(p<0.001)$, and calcification $(p=0.023)$. Multivariable regression analysis showed fibrous plaque (odds ratio $[\mathrm{OR}]: 3.014,95 \%$ confidence interval $[\mathrm{CI}]$ : $1.932-4.702, p<0.001$ ) and nearby bifurcation (OR: $1.750,95 \%$ CI: $1.109-2.761, p=0.016$ ) were independently associated with OCT-erosion with an area stenosis of $<75 \%$.

Conclusions: More than half of OCT-erosions presented with $<75 \%$ area stenosis, having distinct morphological features from those of OCT-erosions with critical stenosis. Fibrous plaque and nearby bifurcation were independently associated with noncritically stenotic OCT-erosion, suggesting that eroded plaques might need individualized treatment.

Key words: Bifurcation, Coronary stenosis, Myocardial infarction, Optical coherence tomography, Plaque erosion

\section{Introduction}

Plaque erosion is the major mechanism of acute coronary thrombosis, only secondary to plaque rupture. Previous pathology and intravascular optical coherence tomography (OCT) studies have suggested that plaque erosion is responsible for about onequarter of ST-segment elevated myocardial infarction (STEMI) cases ${ }^{1,2)}$. Kramer et al. demonstrated that about $60 \%$ of plaque erosion lesions had a lumen area

Address for correspondence: Bo Yu, Department of Cardiology, The 2nd Affiliated Hospital of Harbin Medical University; The Key Laboratory of Myocardial Ischemia, Chinese Ministry of Education. 246 Xuefu Road, Nangang District, Harbin 150086, China. E-mail: dryu_hmu@163.com

Received: August 25, 2020 Accepted for publication: October 30, 2020

Copyright@2021 Japan Atherosclerosis Society

This article is distributed under the terms of the latest version of CC BY-NC-SA defined by the Creative Commons Attribution License.

\section{Advance Publication Journal of Atherosclerosis and Thrombosis}


stenosis of $<75 \%$ in sudden death victims ${ }^{3)}$. Recent clinical studies indicate the feasibility and safety of conservative treatment without stenting in patients with plaque erosion and subcritical stenosis ${ }^{4-7)}$. Moreover, accumulative evidence showed that flow disturbance plays a crucial role in mechanisms of plaque erosion ${ }^{8,9)}$. Local flow disturbance due to coronary lumen narrowing or nearby arterial bifurcation may alter endothelial shear stress and activate platelets ${ }^{10)}$. A recent OCT study demonstrated that in cases with superficial erosion, the composition of the thrombi was related to the degree of luminal narrowing, and the prevalence of fibrin-rich thrombi increased as stenosis severity became milder ${ }^{11)}$. However, morphological features of eroded plaques with mild, moderate, and severe lumen narrowing have not been systemically investigated.

\section{Aim}

The present study aimed to assess morphological features of OCT-defined plaque erosion (OCTerosion) lesions with different lumen area stenosis by using intravascular OCT and to investigate the predictors of OCT-erosion with noncritical stenosis.

\section{Methods}

\section{Study Population}

Between August 2014 and December 2017, a total of 4284 patients with STEMI were admitted to our hospital. Among them, 1660 patients with STEMI underwent OCT imaging of the culprit lesion during emergency intervention and were prospectively enrolled. Patients with cardiac shock, severe kidney dysfunction, chronic total occlusion, extremely tortuous arteries, left main lesion, allergy to contrast, and other conditions that the investigator considered unsuitable were excluded. All OCT images of the 1660 enrolled patients with STEMI were retrospectively analyzed, and 218 patients were excluded during image analysis due to the following reasons: pre-dilation before OCT imaging $(n=31)$, poor OCT image quality or massive thrombus $(n=129)$, and in-stent thrombosis or neoatherosclerosis $(n=58)$. Consequently, 1442 STEMI patients with eligible OCT images of the culprit lesion were analyzed and $348(24.1 \%)$ had OCT-erosion. The study flowchart is shown in Fig. 1.

STEMI was diagnosed when patients had persistent typical chest pain with ST-segment elevation of $>0.1 \mathrm{mV}$ in $\geq 2$ contiguous leads or new left bundle branch block on the electrocardiograms as well as elevated serum cardiac biomarkers (creatine
kinase-MB or troponin T/I). The culprit lesion was identified by coronary angiography, ST-segment alteration on electrocardiograms, and/or regional wall motion abnormalities on cardiac ultrasound. Clinical characteristics including demographics, traditional coronary risk factors, and pre-intervention laboratory tests were collected. Detailed definitions of traditional coronary risk factors are presented in the Supplementary Methods. This study was approved by the ethic community of our hospital and informed consents were obtained from all patients.

\section{Coronary Angiography Analysis}

Patients were treated with a loading dose of dual antiplatelet therapy before intervention. Coronary angiography was performed via the radial or femoral approach after intracoronary injection of nitroglycerin. Coronary angiograms were analyzed using a quantitative coronary angiography analysis system (CAAS 5.10.1; Pie Medical Imaging BV, Maastricht, The Netherlands) by an experienced investigator (S.Z.) who was blinded to the patients' information. Quantitative angiographic data, including distal and proximal reference vessel diameter, minimal vessel diameter, percentage diameter stenosis, and lesion length, were measured post-thrombectomy.

\section{Optical Coherence Tomography Acquisition and} Analysis

OCT was performed under discretion of an intervention cardiologist with the C7-XR/ILUMIEN OCT system (Abbott Vascular, Santa Clara, CA, USA) after restoration of the anterior blood flow. Manual thrombectomy was performed in the setting of initial thrombolysis in myocardial infarction (TIMI) flow grade of $\leq 1$ or extensive thrombus, whereas predilation prior to OCT imaging was not allowed. The OCT imaging catheter was carefully advanced distal to the culprit lesion. The automated pullback was performed while blood was displaced by a short injection of contrast through the guiding catheter. All OCT images were digitally stored and analyzed using off-line review workstation software (Abbott Vascular) in the Intravascular Imaging and Physiology Core Lab of the 2nd Affiliated Hospital of Harbin Medical University by two independent investigators (C.F. and J.D.). When there was discordance between two investigators, a consensus was obtained from a third experienced investigator (J.H.).

All measurements were performed according to previously established consensus and guidelines ${ }^{12)}$. Reference lumen area (RLA) was measured at the largest lumen site proximal or distal to the lesion, but within the same segment with no major intervening 


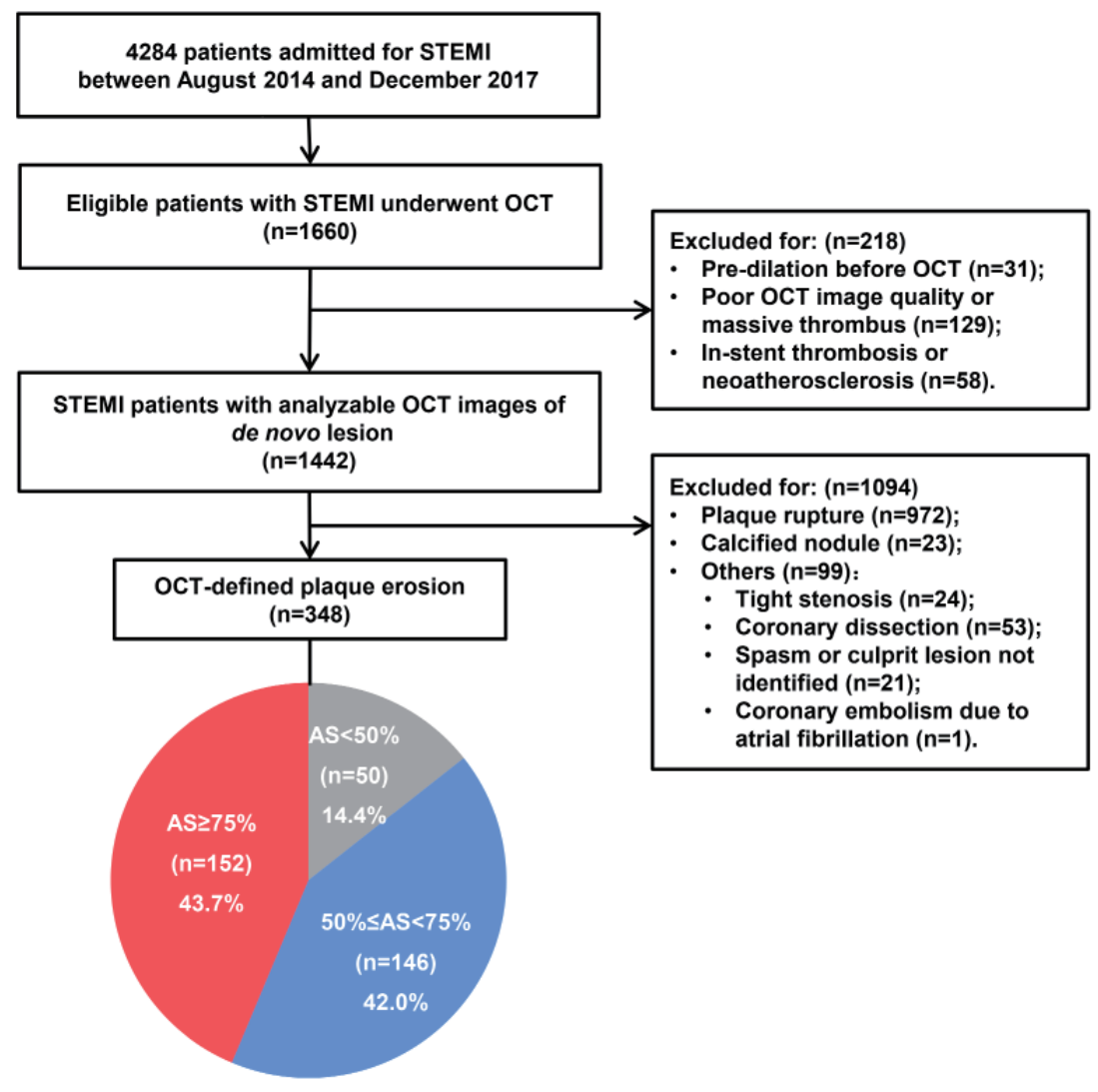

Fig. 1. Study flowchart

AS, area stenosis; OCT, optical coherence tomography; STEMI, ST-segment elevated myocardial infarction.

branches. The mean RLA was calculated as (proximal $R L A+$ distal $R L A) / 2$. The minimal lumen area (MLA) was identified along the length of the culprit lesion and cross-sectionally bounded by the luminal border including the thrombus area (Supplementary Fig. 1). Percentage lumen area stenosis was calculated as (1-MLA/mean RLA)*100\%. OCT-erosion was identified by the presence of attached thrombus overlying an intact fibrous cap, or luminal surface irregularity at the culprit lesion in the absence of thrombus, or attenuation of underlying plaque by thrombus without superficial lipid or calcification immediately proximal or distal to the site of thrombus ${ }^{13)}$. The inter-observer and intra-observer kappa coefficients for OCT-erosion were 0.84 and 0.89 , respectively.

Quantitative and qualitative analyses of plaque features were performed as described in the Supplementary Methods. Nearby bifurcation was defined as a side branch with the diameter of $>1 \mathrm{~mm}$ located $\leq 5 \mathrm{~mm}$ proximally and distally to the site of MLA.

\section{Statistical Analysis}

Statistical analyses were performed by an independent statistician (L.L.) using SPSS version 20.0 (SPSS, Chicago, IL, USA). Categorical variables were presented as number (percentage) and continuous variables were presented as mean \pm standard deviations when normally distributed and as median (interquartile range) when abnormally distributed after testing for normal distribution by the nonparametric one-sample Kolmogorov-Smirnov test. Categorical variables were compared using the Chisquare or Fisher's exact test. Bonferroni's correction was applied for multiple comparisons among the three groups and a $p<0.017$ in a two-group comparison was considered significantly different. Continuous variables were compared with the use of ANOVA or the Kruskal-Wallis $H$ test when appropriate, and posthoc test was used only if $p<0.05$. Multivariable logistic regression analysis was used to identify independent predictors of OCT-erosion with noncritical stenosis ( $<75 \%$ lumen area stenosis). Variables with a $p<0.1$ in the univariable analysis were included in the multivariable model. A two-tailed 
$p<0.05$ was considered as statistically significant.

\section{Results}

Clinical Characteristics and Coronary Angiographic Findings of STEMI Patients with OCT-Erosion

Among 348 culprit OCT-erosions in STEMI patients, $14.4 \%$ had $<50 \%$ lumen area stenosis (Group A), 42.0\% had 50\%-75\% (Group B), and $43.7 \%$ had $\geq 75 \%$ (Group C) (Fig. 1).

The clinical characteristics and coronary angiographic findings are summarized in Table 1 and Supplementary Table 1. As compared with patients in Groups A and B, those in Group C were the oldest $(51.3 \pm 12.8$ years vs. $53.6 \pm 10.0$ years vs. $56.3 \pm 11.1$ years, $p=0.008$ ) and had the highest prevalence of hypertension $(22.0 \%$ vs. $33.6 \%$ vs. $42.1 \%, p=0.029)$. Angiographic analysis showed that $72.0 \%$ of plaque erosions in Group A were located in the left anterior descending artery, followed by $67.8 \%$ in Group B and $53.9 \%$ in Group C $(p=0.039)$. Diameter stenosis of Groups A, B, and C were 53.7\% $\pm 18.3 \%, 62.0 \% \pm$ $13.7 \%$, and $67.8 \% \pm 10.9 \%$, respectively $(p<0.001)$.

\section{Morphological Characteristics of OCT-Erosions with Different Area Stenosis}

OCT findings are shown in Table 2, Supplementary Table 2 and Fig. 2. The prevalence of fibrous plaques was highest in Group A compared with Groups B and C (82.0\% vs. $54.8 \%$ vs. $34.9 \%$, $p$ $<0.001$ ), whereas lipid-rich plaques (LRPs) were most frequent in Group C (16.0\% vs. $43.8 \%$ vs. $62.5 \%$, $p$ $<0.001)$. The prevalence of macrophage accumulation, microvessels, cholesterol crystals, and calcification (including spotty calcification) increased gradiently from Group A to Group B to Group C. Notably, nearby bifurcation was most common in Group A, followed by Groups B and C (72.0\% vs. $67.1 \%$ vs. $55.3 \%, p=0.036)$. The distributions of nearby bifurcation to the site of MLA were similar among the three groups (Supplementary Fig. 2). Layered plaque was least observed in Group A as compared with Groups B and C $(22.0 \%$ vs. $44.5 \%$ vs. $52.0 \%$, $p=0.001$ ), but there was no significant difference in layer thickness and area among the three groups.

Predictors of OCT-Erosion with Noncritical Stenosis In all 348 STEMI patients with OCT-erosion, the following variables with a $p<0.1$ in the univariable analysis (Supplementary Table 3) were tested: age, hypertension, culprit vessel of the left anterior descending artery, multivessel disease, RLA, fibrous plaque, macrophage accumulation, microvessels, cholesterol crystals, calcification, nearby bifurcation, and layered plaque. In multivariable logistic regression analysis, fibrous plaque (odds ratio [OR]: 3.014, 95\% confidence interval [CI]: 1.932-4.702, $p<0.001)$ and nearby bifurcation (OR: 1.750, 95\% CI: 1.1092.761, $p=0.016)$ were independently associated with OCT-erosion with noncritical stenosis $(<75 \%$ lumen area stenosis; vs. OCT-erosion with critical stenosis $[\geq$ 75\% area stenosis]) (Fig. 3).

\section{Discussion}

The present study provided in vivo evidence of morphological characteristics of culprit eroded plaques with different lumen narrowing in patients with STEMI by using OCT. The main findings were as follows: (1) $56.3 \%$ of STEMI patients with culprit OCT-erosion had lumen area stenosis of $<75 \%$; and (2) as compared with critical stenotic OCT-erosion, culprit OCT-erosion with noncritical stenosis occurred more in fibrous plaques and more frequently near arterial bifurcation.

\section{Coronary Lumen Stenosis and Plaque Erosion}

The present study found that $56.3 \%$ of culprit OCT-erosion lesions had a lumen area stenosis of $<$ $75 \%$. Our findings were in line with previous pathological evidence. Kramer et al. reported that $60 \%(30 / 50)$ of culprit erosive plaques were identified with $<75 \%$ cross-sectional luminal narrowingdefined as (1-lumen arealinternal elastic lamina area)* 100 , where the area of the thrombus was excluded from the calculation of percent stenosis-in cases of sudden cardiac death ${ }^{3)}$. In addition, postmortem studies showed culprit plaque erosion was accompanied with approximately $70 \%$ lumen area stenosis (equivalent to a $45 \%$ diameter stenosis) ${ }^{3,14)}$. Consistent with these reports, the present study showed that the average lumen area stenosis for all 348 culprit lesions of OCT-erosion was $67.3 \% \pm$ $17.7 \%$, corresponding to an estimated diameter stenosis of about $43 \%$. However, our quantitative coronary angiography analysis exhibited an average diameter stenosis of $63.3 \% \pm 14.2 \%$. Similar results were obtained in recent intravascular imaging studies on acute coronary syndrome (ACS) patients; culprit erosive lesions had diameter stenoses ranging from $55 \%$ to $77 \%$ at the beginning of emergency intervention ${ }^{1,13,15,16)}$. This disparity could be explained by the presence of residual thrombus within the culprit lesion, which may result in an overestimation of stenosis severity. More specifically, the diameter stenosis assessed by coronary angiography consists of stenosis caused by the atherosclerotic plaque (plaquestenosis) and stenosis caused by the subsequent 
Table 1. Clinical characteristics and coronary angiographic findings of STEMI patients with OCT-erosion

\begin{tabular}{|c|c|c|c|c|c|c|c|}
\hline \multirow[t]{2}{*}{ Variables } & \multicolumn{3}{|c|}{ Area stenosis } & \multicolumn{4}{|c|}{$p$ value } \\
\hline & $\begin{array}{c}\text { Group A } \\
<50 \%(n=50)\end{array}$ & $\begin{array}{c}\text { Group B } \\
50-75 \%(n=146)\end{array}$ & $\begin{array}{c}\text { Group C } \\
\geq 75 \%(n=152)\end{array}$ & $\begin{array}{l}\text { A vs. B vs. } \\
\text { C }\end{array}$ & A vs. B & B vs. C & A vs. C \\
\hline \multicolumn{8}{|l|}{ Clinical characteristics } \\
\hline Age, years & $51.3 \pm 12.8$ & $53.6 \pm 10.0$ & $56.3 \pm 11.1$ & 0.008 & 0.195 & 0.031 & 0.005 \\
\hline Male & $42(84.0)$ & $115(78.8)$ & $119(78.3)$ & 0.673 & NA & NA & NA \\
\hline Smoking status & & & & 0.226 & NA & NA & NA \\
\hline Never & $14(28.0)$ & $38(26.0)$ & $49(32.2)$ & & & & \\
\hline Former & $6(12.0)$ & $7(4.8)$ & $14(9.2)$ & & & & \\
\hline Current & $30(60.0)$ & $101(69.2)$ & $89(58.6)$ & & & & \\
\hline Diabetes mellitus & $5(10.0)$ & $21(14.4)$ & $26(17.1)$ & 0.459 & NA & NA & NA \\
\hline Hypertension & $11(22.0)$ & $49(33.6)$ & $64(42.1)$ & 0.029 & 0.126 & 0.129 & 0.011 \\
\hline Dyslipidemia & $21(42.0)$ & $80(54.8)$ & $65(42.8)$ & 0.079 & NA & NA & NA \\
\hline CKD & $4(8.0)$ & $7(4.8)$ & $9(5.9)$ & 0.697 & NA & NA & NA \\
\hline \multicolumn{8}{|l|}{ Laboratory test } \\
\hline $\mathrm{TC}, \mathrm{mg} / \mathrm{dL}$ & $186.3 \pm 63.7$ & $177.8 \pm 37.4$ & $175.6 \pm 38.7$ & 0.306 & NA & NA & NA \\
\hline $\mathrm{TG}, \mathrm{mg} / \mathrm{dL}$ & $136.7 \pm 74.7$ & $142.1 \pm 78.6$ & $131.8 \pm 78.9$ & 0.526 & NA & NA & NA \\
\hline LDL-C, mg/dL & $109.5 \pm 33.9$ & $117.4 \pm 45.7$ & $109.6 \pm 34.7$ & 0.194 & NA & NA & NA \\
\hline HDL-C, mg/dL & $52.0 \pm 9.7$ & $49.7 \pm 11.7$ & $50.3 \pm 11.4$ & 0.469 & NA & NA & NA \\
\hline cTnI, $\mu \mathrm{g} / \mathrm{L}$ & $2.9(0.3,55.1)$ & $1.5(0.2,8.8)$ & $1.5(0.3,10.0)$ & 0.173 & NA & NA & NA \\
\hline CK-MB, U/L & $19.5(2.9,149.5)$ & $13.2(1.9,64.5)$ & $14.6(1.9,85.0)$ & 0.252 & NA & NA & NA \\
\hline hs-CRP, mg/L & $6.8 \pm 5.3$ & $6.9 \pm 5.1$ & $6.0 \pm 4.9$ & 0.274 & NA & NA & NA \\
\hline pro-BNP, pg/mL & $441.0(77.5,1106.5)$ & $305.0(79.5,1376.0)$ & $262.0(60.3,1242.3)$ & 0.799 & NA & NA & NA \\
\hline $\begin{array}{l}\text { STEMI onset to OCT imaging time, min } \\
\text { Coronary angiographic findings }\end{array}$ & $326.0(210.0,522.0)$ & $285.5(187.8,456.0)$ & $316.0(205.0,517.0)$ & 0.454 & NA & NA & NA \\
\hline Culprit vessel & & & & 0.039 & 0.529 & 0.063 & 0.076 \\
\hline LAD & $36(72.0)$ & $99(67.8)$ & $82(53.9)$ & & & & \\
\hline LCX & $2(4.0)$ & $13(8.9)$ & $13(8.6)$ & & & & \\
\hline RCA & $12(24.0)$ & $34(23.3)$ & $57(37.5)$ & & & & \\
\hline Segment & & & & 0.201 & NA & NA & NA \\
\hline Proximal & $20(40.0)$ & $76(52.1)$ & $63(41.4)$ & & & & \\
\hline Mid & $18(36.0)$ & $51(34.9)$ & $63(41.4)$ & & & & \\
\hline Distal & $12(24.0)$ & $19(13.0)$ & $26(17.1)$ & & & & \\
\hline Lesion length, mm & $18.8 \pm 8.7$ & $18.0 \pm 8.8$ & $18.2 \pm 9.0$ & 0.850 & NA & NA & NA \\
\hline RLD, mm & $3.2 \pm 0.6$ & $3.1 \pm 0.6$ & $3.1 \pm 0.5$ & 0.231 & NA & NA & NA \\
\hline MLD, mm & $1.5 \pm 0.7$ & $1.2 \pm 0.5$ & $1.0 \pm 0.4$ & $<0.001$ & $<0.001$ & 0.002 & $<0.001$ \\
\hline DS, \% & $53.7 \pm 18.3$ & $62.0 \pm 13.7$ & $67.8 \pm 10.9$ & $<0.001$ & 0.001 & $<0.001$ & 0.001 \\
\hline Initial TIMI flow 0-1 & $31(62.0)$ & $98(67.1)$ & $97(63.8)$ & 0.748 & NA & NA & NA \\
\hline Multivessel disease & $12(24.0)$ & $44(30.1)$ & $60(39.5)$ & 0.074 & NA & NA & NA \\
\hline Thrombolysis & $3(6.0)$ & $7(4.8)$ & $9(5.9)$ & 0.898 & NA & NA & NA \\
\hline Thrombus aspiration & $36(72.0)$ & $126(86.3)$ & $121(79.6)$ & 0.063 & NA & NA & NA \\
\hline
\end{tabular}

Values expressed as $n(\%)$, mean $\pm \mathrm{SD}$, or median (25th-75th percentiles).

A $p$-value $<0.05$ (A vs. B vs. C) or $p$-value $<0.017$ (two-group comparison) was considered statistically significant.

$\mathrm{CKD}$, chronic kidney disease; CK-MB, creatine kinase-MB; cTnI, cardiac troponin I; DS, diameter stenosis; HDL-C, high-density lipoprotein cholesterol; hs-CRP, high-sensitive C-reactive protein; LAD, left anterior descending artery; LCX, left circumflex artery; LDL-C, low-density lipoprotein cholesterol; MLD, minimal lumen diameter; OCT, optical coherence tomography; pro-BNP, pro-type B natriuretic peptide; RCA, right coronary artery; RLD, reference lumen diameter; TC, total cholesterol; TG, triglyceride; TIMI, thrombolysis in myocardial infarction. 
Table 2. Morphological characteristics of plaque erosions with different area stenosis detected by OCT

\begin{tabular}{|c|c|c|c|c|c|c|c|}
\hline \multirow[t]{2}{*}{ Variables } & \multicolumn{3}{|c|}{ Area stenosis } & \multicolumn{4}{|c|}{$p$ value } \\
\hline & $\begin{array}{c}\text { Group A } \\
<50 \%(n=50)\end{array}$ & $\begin{array}{c}\text { Group B } \\
50-75 \%(n=146)\end{array}$ & $\begin{array}{c}\text { Group C } \\
\geq 75 \%(n=152)\end{array}$ & $\begin{array}{c}\text { A vs. B vs. } \\
\text { C }\end{array}$ & A vs. B & B vs. C & A vs. C \\
\hline Area stenosis, $\%$ & $33.3 \pm 14.4$ & $64.3 \pm 7.0$ & $81.4 \pm 4.1$ & $<0.001$ & $<0.001$ & $<0.001$ & $<0.001$ \\
\hline MLA, $\mathrm{mm}^{2}$ & $5.7 \pm 3.1$ & $2.5 \pm 1.1$ & $1.5 \pm 0.4$ & $<0.001$ & $<0.001$ & $<0.001$ & $<0.001$ \\
\hline RLA, $\mathrm{mm}^{2}$ & $8.4 \pm 3.7$ & $7.2 \pm 2.8$ & $8.1 \pm 2.5$ & 0.008 & 0.031 & 0.031 & 1.000 \\
\hline Fibrous plaque & $41(82.0)$ & $80(54.8)$ & $53(34.9)$ & $<0.001$ & 0.001 & 0.001 & $<0.001$ \\
\hline Lipid plaque & $9(18.0)$ & $66(45.2)$ & $99(65.1)$ & $<0.001$ & 0.001 & 0.001 & $<0.001$ \\
\hline Lipid length, mm & $10.5 \pm 7.3$ & $10.2 \pm 5.3$ & $10.6 \pm 5.2$ & 0.884 & NA & NA & NA \\
\hline Mean lipid arc, ${ }^{\circ}$ & $207.0 \pm 40.3$ & $209.7 \pm 45.5$ & $228.5 \pm 50.0$ & 0.033 & 1.000 & 0.041 & 0.595 \\
\hline Maximal lipid arc, ${ }^{\circ}$ & $295.3 \pm 75.4$ & $288.5 \pm 61.7$ & $310.7 \pm 62.8$ & 0.084 & NA & NA & NA \\
\hline Minimal FCT, $\mu \mathrm{m}$ & $87.6 \pm 28.8$ & $94.6 \pm 36.1$ & $91.0 \pm 42.9$ & 0.793 & NA & NA & NA \\
\hline LRP & $8(16.0)$ & $64(43.8)$ & $95(62.5)$ & $<0.001$ & $<0.001$ & 0.001 & $<0.001$ \\
\hline TCFA & $2(4.0)$ & $13(8.9)$ & $32(21.1)$ & 0.001 & 0.260 & 0.003 & 0.005 \\
\hline Macrophage & $8(16.0)$ & $82(56.2)$ & $100(65.8)$ & $<0.001$ & $<0.001$ & 0.088 & $<0.001$ \\
\hline Microvessels & $8(16.0)$ & $48(32.9)$ & $60(39.5)$ & 0.009 & 0.023 & 0.236 & 0.002 \\
\hline Cholesterol crystals & $3(6.0)$ & $23(15.8)$ & $45(29.6)$ & $<0.001$ & 0.079 & 0.004 & 0.001 \\
\hline Calcification & $8(16.0)$ & $42(28.8)$ & $55(36.2)$ & 0.023 & 0.074 & 0.172 & 0.008 \\
\hline Spotty calcification & $3(6.0)$ & $32(21.9)$ & $42(27.6)$ & 0.006 & 0.011 & 0.254 & 0.001 \\
\hline Nearby bifurcation & $36(72.0)$ & $98(67.1)$ & $84(55.3)$ & 0.036 & 0.522 & 0.036 & 0.037 \\
\hline Distance from bifurcation to MLA, $\mathrm{mm}$ & $2.5 \pm 1.7$ & $2.3 \pm 1.5$ & $2.4 \pm 1.4$ & 0.710 & NA & NA & NA \\
\hline Layered plaque & $11(22.0)$ & $65(44.5)$ & $79(52.0)$ & 0.001 & 0.005 & 0.198 & $<0.001$ \\
\hline Layer thickness, $\mu \mathrm{m}$ & $655.0(505.0,787.5)$ & $575.0(465.0,775.0)$ & $570.0(435.0,775.0)$ & 0.760 & $\mathrm{NA}$ & NA & $\mathrm{NA}$ \\
\hline Layer area, $\mathrm{mm}^{2}$ & $1.4(1.0,2.4)$ & $1.2(0.8,2.1)$ & $1.4(0.9,2.1)$ & 0.573 & NA & NA & NA \\
\hline
\end{tabular}

Values expressed as $n(\%)$, mean $\pm \mathrm{SD}$, or median (25th-75th percentiles).

A $p$-value $<0.05$ (A vs. B vs. C) or $p$-value $<0.017$ (two-group comparison) was considered statistically significant.

FCT, fibrous cap thickness; LRP, lipid-rich plaque; MLA, minimal lumen area; OCT, optical coherence tomography; RLA, reference lumen area; TCFA, thin cap fibroatheroma.

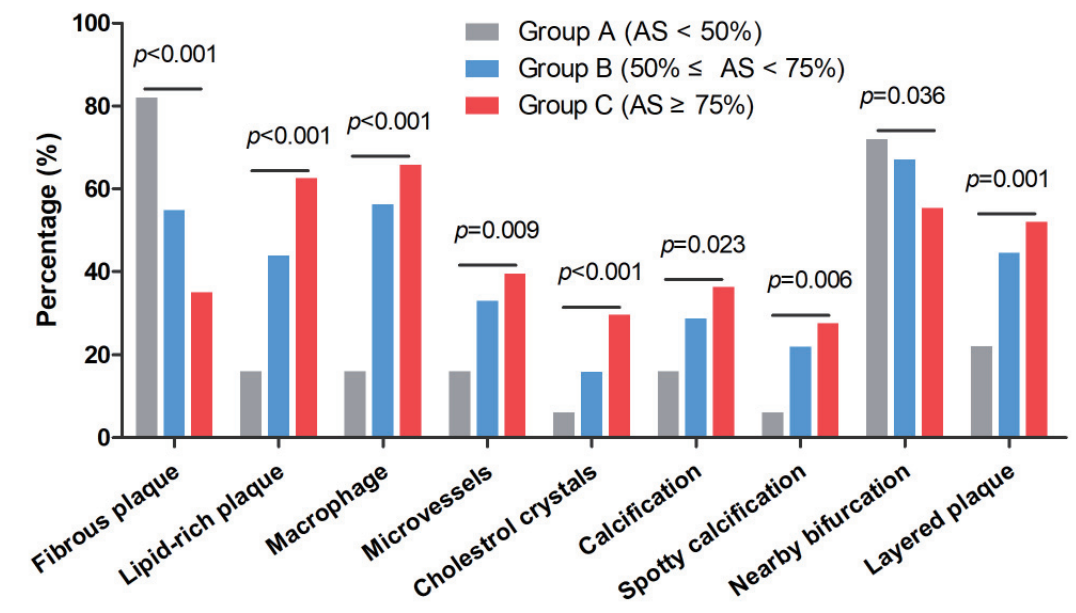

Fig. 2. Morphological characteristics of OCT-erosion lesions with different area stenosis detected by optical coherence tomography Compared with Groups B and C, fibrous plaque and nearby bifurcation were most common in Group A. The prevalence of lipid-rich plaque, macrophage accumulation, microvessels, cholesterol crystals, calcification (including spotty calcification), and layered plaque increased gradually from Group A to Group B to Group C. AS, area stenosis; OCT, optical coherence tomography. 


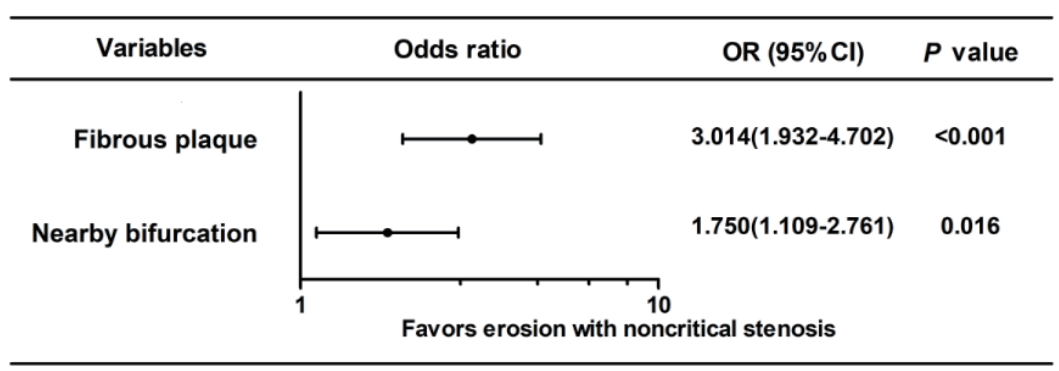

Fig. 3. Multivariable logistic regression analysis

Fibrous plaque (OR: 3.014, 95\%CI: 1.932-4.702, $p<0.001$ ) and nearby bifurcation (OR: $1.750,95 \%$ CI: $1.109-2.761, p=0.016$ ) were independently associated with OCT-erosion with noncritical stenosis (lumen area stenosis $<75 \%$ ). CI, confidence interval; OR, odds ratio.

thrombus (thrombus-stenosis). Meanwhile, the assessment of diameter stenosis in coronary angiography can be influenced by different viewing angles. Therefore, using OCT in this study enabled not only the diagnosis of plaque erosion but also a more accurate analysis of lumen area stenosis, which was comparable with pathological observation and avoided the defect of two-dimensional observation of angiography.

\section{Underlying Plaque Phenotype of Superficial Erosion}

Pathological and clinical imaging studies suggested plaque erosion was not a homogeneous entity because of the heterogeneous underlying substrates $^{14,17-19)}$. Unlike plaque rupture merely involving a thin-cap fibroatheroma, plaque erosion occurred in plaques rich in smooth muscle cells and extracellular matrix components such as proteoglycans and hyaluronan, in which a lipid pool was absent or deep-seated ${ }^{14,20)}$. Our group recently reported that plaque erosion was most frequently detected in fibrous plaques, following thick-cap fibroatheromas, and least in thin-cap fibroatheromas ${ }^{17)}$. Using multiple intravascular imaging modalities, Yamaguchi et al. suggested OCT-erosion lesions had at least two distinct plaque morphologies of different lipid core burden, including fibrous plaque and LRP ${ }^{18)}$. Moreover, in ACS patients, the absence of LRP underneath an eroded plaque predicted better clinical outcomes ${ }^{19)}$. In the present study, fibrous plaque was independently associated with culprit OCT-erosion with noncritical stenosis ( $<75 \%$ lumen area stenosis), whereas lipid plaque related to OCT-erosion with critical stenosis. This is consistent with previous pathological findings that plaque erosion lesion with noncritical stenosis had a smaller necrotic core area and macrophage area than that with critical stenosis ${ }^{3)}$. A recent OCT study of ACS patients also demonstrated the prevalence of LRP was lowest in cases of plaque erosion with mild stenosis ${ }^{11)}$.

Additionally, the present study revealed a lower level of coronary plaque vulnerability of eroded plaque with noncritical stenosis, such as less frequent LRP, macrophage accumulation, microvessels, cholesterol crystals, calcification (including spotty calcification), and layered plaques. Previous studies suggested that these plaque features reflect the vulnerability of coronary lesions to thrombus formation and are associated with future adverse events ${ }^{21-26}$. Layered plaques indicated a previous thrombotic event and subsequent healing of the coronary lesion ${ }^{27)}$. With coronary stenosis increasing, the prevalence of layered plaque increased, suggesting a higher risk of recurrent thrombotic event in critical stenotic OCT-erosion.

\section{Nearby Bifurcation and OCT-Erosion}

Accumulative evidence has highlighted the role of local flow disturbance in the occurrence of plaque erosion $^{8,28,29)}$. As previous experimental work reported that flow disturbance potentiates endothelial cell dysfunction through toll-like receptor 2 stimulation and neutrophil recruitment, which in turn promotes endothelial detachment and acute coronary thrombosis ${ }^{8,30,31)}$. For coronary atherosclerotic lesions, local hemodynamic changes can result from coronary lumen stenosis, branches, and vessel bends ${ }^{32}$. A recent clinical study of STEMI patients suggested that nearby bifurcation, which could give rise to disturbed blood flow, was a local anatomical risk factor of superficial erosion ${ }^{1)}$. The present study found nearby bifurcation independently associated with OCTerosion with noncritical stenosis. As the noncritical area stenosis contributes less to local flow disturbance, nearby bifurcation may play an important role in flow disturbance, leading to plaque erosion (Fig.4A). In contrast, critically stenotic OCT-erosion lesion had a 
(A) Plaque erosion with noncritical stenosis
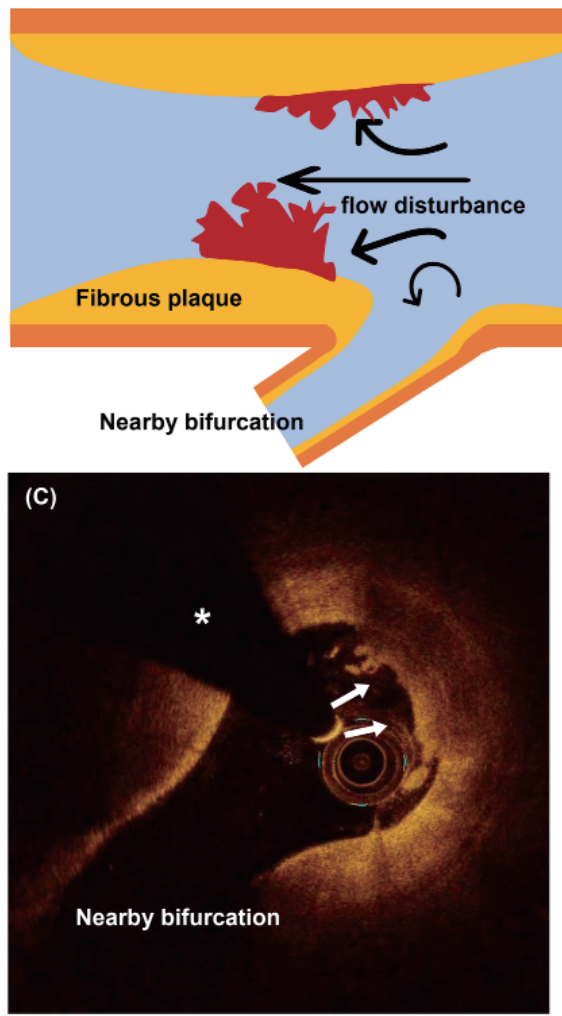

(B) Plaque erosion with critical stenosis
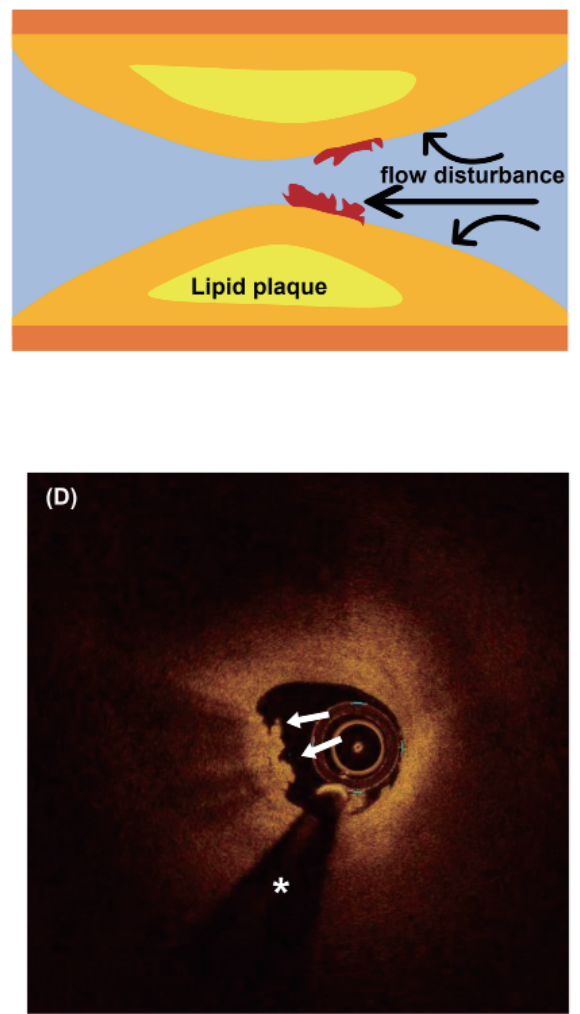

Fig.4. Schematic drawings and representative optical coherence tomography (OCT) images of culprit OCT-erosion with different coronary stenosis

Fig. A and B are schematic drawings of OCT-erosion with noncritical and critical stenosis. Flow disturbance resulting from nearby bifurcation or lumen stenosis was a crucial mechanism for plaque erosion. Fig. C showed OCT-erosion with noncritical stenosis, identified as residual thrombus (white arrows) overlying a fibrous plaque, accompanying nearby bifurcation. Fig. D showed OCT-erosion with critical stenosis, identified as residual thrombus (white arrows) overlying a lipid plaque, and no nearby bifurcation was observed. *Guidewire.

lower frequency of nearby bifurcation but had a more narrowed lumen, where the upstream laminar flow converts into turbulent flow, subsequently resulting in superficial erosion (Fig.4B). Additionally, a recent OCT study showed that the composition of thrombus was different in plaque erosions with different severities of lumen narrowing, suggesting that plaque erosion with different lumen narrowing might have distinct onset mechanisms ${ }^{11)}$. Future experimental studies are warranted to illustrate the detail mechanisms for plaque erosions with different stenosis.

\section{Clinical Implications}

The present study provided in vivo evidence for morphological features of eroded plaques with noncritical and critical stenosis and the novel insight that pathophysiological mechanisms may be different in relation to nearby bifurcation. These findings are also supported by recent studies on the safety and feasibility of conservative treatment without emergency stent implantation for selected myocardial infarction patients (mild stenosis and good TIMI flow) with culprit plaque erosion ${ }^{4-7)}$. Generally, stent implantation was recommended to improve the artery lumen and flow space in patients with STEMI ${ }^{33)}$. However, in lesions with noncritical stenosis, fibrous plaque and nearby bifurcation were more frequent while the plaque vulnerable features (i.e. less frequent LRP, macrophage accumulations, et al.) were less. Conservative medication therapy might be feasible and able to avoid the risk of stenting-related complications, including loss of small branches. Additional research is needed to investigate the detailed mechanism of plaque erosion onset and a more tailored treatment therapy to individual patients.

\section{Limitations}

The present study had some limitations. First, this was a single-center, observational study in STEMI patients, and OCT imaging was performed under the discretion of an interventional cardiologist. Thus, 
there might have been some selection bias and our conclusions might not be generalizable. Second, the sample size of this study was limited; a large-scale study is needed. Third, the definition of OCT-erosion was somewhat an exclusion diagnosis and has not been validated in pathohistological studies. The current OCT system cannot visualize endothelial cells, making it difficult to distinguish thrombosis caused by tight stenosis from that caused by erosion. However, OCT was the hitherto unique modality to identify in vivo plaque erosion and this definition had high reproducibility, as reported by many previous studies. Fourth, limitations of near-infrared light partially reduced the ability of OCT to detect microstructures underlying a lipid plaque or thrombus, so it might be difficult to distinguish small ruptures filled with thrombus from erosion and to analyze plaque burden and remodeling. The residual thrombus might also influence the measurement of the lumen area. Thus, OCT images were analyzed consecutively to minimize the error. Fifth, due to the large thrombus burden and poor blood flow in most STEMI patients, thrombus aspiration was an efficient procedure to early recanalize the occluded artery and to better assess coronary lesions during emergency intervention. In this study, manual thrombectomy was performed in $81.3 \%(283 / 348)$ of the patients, and a similar prevalence of thrombectomy has been found in previous OCT studies on STEMI patients, ${ }^{1,34-36}$. The frequency of thrombus aspiration was comparable among the three groups, so the potential effect of thrombus aspiration on lesion morphology was similar among the three groups. Sixth, OCT measurement of thrombus was not performed in consideration of the potential influence of thrombectomy, and those images with massive thrombus influencing OCT analysis were excluded from this study (Fig. 1).

\section{Conclusion}

In STEMI patients, more than half of OCTerosion lesions presented with $<75 \%$ lumen stenosis, which had distinct morphological features from those of OCT-erosion with severe lumen stenosis. Fibrous plaque and nearby bifurcation detected by OCT were independently associated with the presence of noncritically stenotic OCT-erosion. Further studies are warranted to investigate a more tailored treatment therapy to individual patients.

\section{Acknowledgements}

The authors sincerely thank all colleagues and patients who participated in this study.

\section{Funding}

This work was supported by the National Key R \& D Program of China (grant No. 2016YFC1301100 to B.Y.), National Natural Science Foundation of China (grant No. 81827806 to B.Y. and No. 82072091 to J.D.), and Natural Science Foundation of Heilongjiang Province (YQ2020H017 to J.D.).

\section{References}

1) Dai J, Xing L, Jia H, Zhu Y, Zhang S, Hu S, Lin L, Ma L, Liu H, Xu M, Ren X, Yu H, Li L, Zou Y, Zhang S, Mintz GS, Hou J and Yu B: In vivo predictors of plaque erosion in patients with ST-segment elevation myocardial infarction: a clinical, angiographical, and intravascular optical coherence tomography study. Eur Heart J, 2018; 39: 2077-2085

2) Arbustini E, Dal Bello B, Morbini P, Burke AP, Bocciarelli M, Specchia G and Virmani R: Plaque erosion is a major substrate for coronary thrombosis in acute myocardial infarction. Heart, 1999; 82: 269-272

3) Kramer MC, Rittersma SZ, de Winter RJ, Ladich ER, Fowler DR, Liang YH, Kutys R, Carter-Monroe N, Kolodgie FD, van der Wal AC and Virmani R: Relationship of thrombus healing to underlying plaque morphology in sudden coronary death. J Am Coll Cardiol, 2010; 55: 122-132

4) Jia H, Dai J, Hou J, Xing L, Ma L, Liu H, Xu M, Yao Y, Hu S, Yamamoto E, Lee H, Zhang S, Yu B and Jang IK: Effective anti-thrombotic therapy without stenting: intravascular optical coherence tomography-based management in plaque erosion (the EROSION study). Eur Heart J, 2017; 38: 792-800

5) Xing L, Yamamoto E, Sugiyama T, Jia H, Ma L, Hu S, Wang C, Zhu Y, Li L, Xu M, Liu H, Bryniarski K, Hou J, Zhang S, Lee H, Yu B and Jang IK: EROSION Study (Effective Anti-Thrombotic Therapy Without Stenting: Intravascular Optical Coherence Tomography-Based Management in Plaque Erosion): A 1-Year Follow-Up Report. Circ Cardiovasc Interv, 2017; 10

6) Souteyrand G, Amabile N, Combaret N, Hammas S, Prati F, Berry C, Pereira B, Lusson JR, Caussin C and Motreff P: Invasive management without stents in selected acute coronary syndrome patients with a large thrombus burden: a prospective study of optical coherence tomography guided treatment decisions. EuroIntervention, 2015; 11: 895-904

7) Prati F, Uemura S, Souteyrand G, Virmani R, Motreff P, Di Vito L, Biondi-Zoccai G, Halperin J, Fuster V, Ozaki $\mathrm{Y}$ and Narula J: OCT-based diagnosis and management of STEMI associated with intact fibrous cap. JACC Cardiovasc Imaging, 2013; 6: 283-287

8) Franck G, Mawson T, Sausen G, Salinas M, Masson GS, Cole A, Beltrami-Moreira M, Chatzizisis Y, Quillard T, Tesmenitsky Y, Shvartz E, Sukhova GK, Swirski FK, Nahrendorf M, Aikawa E, Croce KJ and Libby P: Flow Perturbation Mediates Neutrophil Recruitment and Potentiates Endothelial Injury via TLR2 in Mice: Implications for Superficial Erosion. Circ Res, 2017; 121: 
$31-42$

9) Libby P, Pasterkamp G, Crea F and Jang IK: Reassessing the Mechanisms of Acute Coronary Syndromes. Circ Res, 2019; 124: 150-160

10) Morbiducci U, Kok AM, Kwak BR, Stone PH, Steinman DA and Wentzel JJ: Atherosclerosis at arterial bifurcations: evidence for the role of haemodynamics and geometry. Thromb Haemost, 2016; 115: 484-492

11) Kurihara $O$, Takano M, Soeda T, Fracassi F, Araki $M$, Nakajima A, McNulty I, Lee H, Mizuno K and Jang IK: Degree of luminal narrowing and composition of thrombus in plaque erosion. J Thromb Thrombolysis, 2020

12) Prati F, Regar E, Mintz GS, Arbustini E, Di Mario C, Jang IK, Akasaka T, Costa M, Guagliumi G, Grube E, Ozaki Y, Pinto F, Serruys PW and Expert's OCTRD: Expert review document on methodology, terminology, and clinical applications of optical coherence tomography: physical principles, methodology of image acquisition, and clinical application for assessment of coronary arteries and atherosclerosis. Eur Heart J, 2010; 31: 401-415

13) Jia $\mathrm{H}$, Abtahian F, Aguirre AD, Lee $S$, Chia $S$, Lowe $H$, Kato K, Yonetsu T, Vergallo R, Hu S, Tian J, Lee H, Park SJ, Jang YS, Raffel OC, Mizuno K, Uemura S, Itoh T, Kakuta T, Choi SY, Dauerman HL, Prasad A, Toma C, McNulty I, Zhang S, Yu B, Fuster V, Narula J, Virmani R and Jang IK: In vivo diagnosis of plaque erosion and calcified nodule in patients with acute coronary syndrome by intravascular optical coherence tomography. J Am Coll Cardiol, 2013; 62: 1748-1758

14) Farb A, Burke AP, Tang AL, Liang TY, Mannan P, Smialek $\mathrm{J}$ and Virmani R: Coronary plaque erosion without rupture into a lipid core. A frequent cause of coronary thrombosis in sudden coronary death. Circulation, 1996; 93: 1354-1363

15) Yamamoto E, Yonetsu T, Kakuta T, Soeda T, Saito Y, Yan BP, Kurihara O, Takano M, Niccoli G, Higuma T, Kimura S, Minami Y, Ako J, Adriaenssens T, Boeder NF, Nef HM, Fracassi F, Sugiyama T, Lee H, Crea F, Kimura $\mathrm{T}$, Fujimoto JG, Fuster $\mathrm{V}$ and Jang IK: Clinical and Laboratory Predictors for Plaque Erosion in Patients With Acute Coronary Syndromes. J Am Heart Assoc, 2019; 8: e012322

16) Niccoli G, Montone RA, Di Vito L, Gramegna M, Refaat H, Scalone G, Leone AM, Trani C, Burzotta F, Porto I, Aurigemma C, Prati F and Crea F: Plaque rupture and intact fibrous cap assessed by optical coherence tomography portend different outcomes in patients with acute coronary syndrome. Eur Heart J, 2015; 36: 1377 1384

17) Dai J, Fang C, Zhang S, Hou J, Xing L, Li L, Wang Y, Wang J, Wang Y, Tu Y, Zhang X, Liu H, Xu M, Ren X, Ma L, Yu H, Wei G, Zhang S, Mintz GS and Yu B: Not All Plaque Erosions Are Equal: Novel Insights From 1,660 Patients With STEMI: A Clinical, Angiographic, and Intravascular OCT Study. JACC Cardiovasc Imaging, 2020; 13: 516-518

18) Yamaguchi M, Sugiyama T, Hoshino M, Kanaji Y, Hada M, Usui E, Yonetsu T and Kakuta T: Two distinct phenotypes of plaque erosion assessed by multimodality intracoronary imaging: a case series. Eur Heart J Case
Rep, 2020; 4: 1-5

19) Hoshino M, Yonetsu T, Usui E, Kanaji Y, Ohya H, Sumino Y, Yamaguchi M, Hada M, Hamaya R, Kanno Y, Murai T, Lee T and Kakuta T: Clinical Significance of the Presence or Absence of Lipid-Rich Plaque Underneath Intact Fibrous Cap Plaque in Acute Coronary Syndrome. J Am Heart Assoc, 2019; 8: e011820

20) Kolodgie FD, Burke AP, Farb A, Weber DK, Kutys R, Wight TN and Virmani R: Differential accumulation of proteoglycans and hyaluronan in culprit lesions: insights into plaque erosion. Arterioscler Thromb Vasc Biol, 2002; 22: 1642-1648

21) Dai J, Tian J, Hou J, Xing L, Liu S, Ma L, Yu H, Ren X, Dong N and Yu B: Association between cholesterol crystals and culprit lesion vulnerability in patients with acute coronary syndrome: An optical coherence tomography study. Atherosclerosis, 2016; 247: 111-117

22) Tian J, Hou J, Xing L, Kim SJ, Yonetsu T, Kato K, Lee H, Zhang S, Yu B and Jang IK: Significance of intraplaque neovascularisation for vulnerability: optical coherence tomography study. Heart, 2012; 98: 1504-1509

23) Ehara S, Kobayashi Y, Yoshiyama M, Shimada K, Shimada Y, Fukuda D, Nakamura Y, Yamashita H, Yamagishi H, Takeuchi K, Naruko T, Haze K, Becker AE, Yoshikawa J and Ueda M: Spotty calcification typifies the culprit plaque in patients with acute myocardial infarction: an intravascular ultrasound study. Circulation, 2004; 110: 3424-3429

24) Xing L, Higuma T, Wang Z, Aguirre AD, Mizuno K, Takano M, Dauerman HL, Park SJ, Jang Y, Kim CJ, Kim SJ, Choi SY, Itoh T, Uemura S, Lowe $\mathrm{H}$, Walters DL, Barlis P, Lee S, Lerman A, Toma C, Tan JWC, Yamamoto E, Bryniarski K, Dai J, Zanchin T, Zhang S, Yu B, Lee H, Fujimoto J, Fuster V and Jang IK: Clinical Significance of Lipid-Rich Plaque Detected by Optical Coherence Tomography: A 4-Year Follow-Up Study. J Am Coll Cardiol, 2017; 69: 2502-2513

25) Usui E, Mintz GS, Lee T, Matsumura M, Zhang Y, Hada M, Yamaguchi M, Hoshino M, Kanaji Y, Sugiyama T, Murai T, Yonetsu T, Kakuta T and Maehara A: Prognostic impact of healed coronary plaque in non-culprit lesions assessed by optical coherence tomography. Atherosclerosis, 2020; 309: 1-7

26) Montone RA, Vetrugno V, Camilli M, Russo M, Fracassi F, Khan SQ, Doshi SN, Townend JN, Ludman PF, Trani C, Niccoli G and Crea F: Macrophage infiltrates in coronary plaque erosion and cardiovascular outcome in patients with acute coronary syndrome. Atherosclerosis, 2020

27) Vergallo R and Crea F: Atherosclerotic Plaque Healing. N Engl J Med, 2020; 383: 846-857

28) Quillard T, Franck G, Mawson T, Folco E and Libby P: Mechanisms of erosion of atherosclerotic plaques. Curr Opin Lipidol, 2017; 28: 434-441

29) Yamamoto E, Thondapu V, Poon E, Sugiyama T, Fracassi F, Dijkstra J, Lee H, Ooi A, Barlis P and Jang IK: Endothelial Shear Stress and Plaque Erosion: A Computational Fluid Dynamics and Optical Coherence Tomography Study. JACC Cardiovasc Imaging, 2019; 12: 374-375

30) Quillard T, Araujo HA, Franck G, Shvartz E, Sukhova G 
and Libby P: TLR2 and neutrophils potentiate endothelial stress, apoptosis and detachment: implications for superficial erosion. Eur Heart J, 2015; 36: 1394-1404

31) Pedicino D, Vinci R, Giglio AF, Pisano E, Porto I, Vergallo R, Russo G, Ruggio A, D’Aiello A, Flego D, Annibali G, Trotta F, Piacentini R, Niccoli G, Liuzzo G and Crea F: Alterations of Hyaluronan Metabolism in Acute Coronary Syndrome: Implications for Plaque Erosion. J Am Coll Cardiol, 2018; 72: 1490-1503

32) Nakazawa G, Yazdani SK, Finn AV, Vorpahl M, Kolodgie FD and Virmani R: Pathological findings at bifurcation lesions: the impact of flow distribution on atherosclerosis and arterial healing after stent implantation. J Am Coll Cardiol, 2010; 55: 1679-1687

33) Ibanez B, James S, Agewall S, Antunes MJ, BucciarelliDucci C, Bueno H, Caforio ALP, Crea F, Goudevenos JA, Halvorsen S, Hindricks G, Kastrati A, Lenzen MJ, Prescott E, Roffi M, Valgimigli M, Varenhorst C, Vranckx P, Widimsky P and Group ESCSD: 2017 ESC Guidelines for the management of acute myocardial infarction in patients presenting with ST-segment elevation: The Task Force for the management of acute myocardial infarction in patients presenting with ST-segment elevation of the European Society of Cardiology (ESC). Eur Heart J, 2018; 39: 119-177
34) Saia F, Komukai K, Capodanno D, Sirbu V, Musumeci G, Boccuzzi G, Tarantini G, Fineschi M, Tumminello G, Bernelli C, Niccoli G, Coccato M, Bordoni B, Bezerra H, Biondi-Zoccai G, Virmani R, Guagliumi $G$ and Investigators $\mathrm{O}$ : Eroded Versus Ruptured Plaques at the Culprit Site of STEMI: In Vivo Pathophysiological Features and Response to Primary PCI. JACC Cardiovasc Imaging, 2015; 8: 566-575

35) Higuma T, Soeda T, Abe N, Yamada M, Yokoyama H, Shibutani S, Vergallo R, Minami Y, Ong DS, Lee H, Okumura $\mathrm{K}$ and Jang IK: A Combined Optical Coherence Tomography and Intravascular Ultrasound Study on Plaque Rupture, Plaque Erosion, and Calcified Nodule in Patients With ST-Segment Elevation Myocardial Infarction: Incidence, Morphologic Characteristics, and Outcomes After Percutaneous Coronary Intervention. JACC Cardiovasc Interv, 2015; 8: 1166-1176

36) Kajander OA, Pinilla-Echeverri N, Jolly SS, Bhindi R, Huhtala H, Niemela K, Fung A, Vijayaraghavan R, Alexopoulos D and Sheth T: Culprit plaque morphology in STEMI - an optical coherence tomography study: insights from the TOTAL-OCT substudy. EuroIntervention, 2016; 12: $716-723$ 


\section{Supplementary Methods}

\section{Definitions of Traditional Coronary Risk Factors}

Cigarette smoking status was identified by personal history and was categorized into current smoker (active smoking within 1 month), former smoker (smoking cessation of $>1$ month), and nonsmoker $^{377}$. Hypertension was defined as documented history of hypertension or a systolic blood pressure of $\geq 140 \mathrm{mmHg}$, diastolic blood pressure of $\geq 90$ $\mathrm{mmHg}$, or anti-hypertension therapy at admission. Diabetes mellitus was diagnosed in a patient who met at least one of the following criteria: documented history of diabetes mellitus, use of hypoglycemia agents, fasting glucose of $\geq 126 \mathrm{mg} / \mathrm{dL}$, 2-hour plasma glucose level of $\geq 200 \mathrm{mg} / \mathrm{dL}$ in the oral glucose tolerance test, classic symptom with casual plasma glucose level of $\geq 200 \mathrm{mg} / \mathrm{dL}$, or hemoglobin A1c of $\geq$ $6.5 \%$. Dyslipidemia was diagnosed in patients with a history of hyperlipidemia, receiving lipid-lowering treatment, or newly diagnosed with hyperlipidemia (total cholesterol level of $\geq 220 \mathrm{mg} / \mathrm{dL}$, triglycerides of $\geq 150 \mathrm{mg} / \mathrm{dL}$, low-density lipoprotein cholesterol of $\geq$ $140 \mathrm{mg} / \mathrm{dL}$, or high-density lipoprotein cholesterol of $\leq 40 \mathrm{mg} / \mathrm{dL}$ ). We calculated the estimated glomerular filtration rate (eGFR) for each patient using the 2009 Chronic Kidney Disease Epidemiology Collaboration equation, and chronic kidney disease was defined as an eGFR of $<60 \mathrm{~mL} / \mathrm{min}$ per $1.73 \mathrm{~m}^{2}$ for $\geq 3$ months ${ }^{38)}$.

\section{Quantitative and Qualitative Analyses of Plaque Features}

The underlying plaque phenotypes were classified as fibrous plaque or lipid plaque. Fibrous plaque was identified using optical coherence tomography (OCT) by a homogeneous high OCT signal region and lipid plaque was identified by a poor OCT signal region with a diffused border. For lipid plaques, the lipid length was measured on the longitudinal view of the culprit lesion and the lipid arc was measured per 1 $\mathrm{mm}$ in the lipid segment. Minimal fibrous cap thickness (FCT) was measured three times in the thinnest region of the fibrous cap overlying the lipid pool and a mean value was obtained. A lipid-rich plaque (LRP) was recorded when the lipid arc was $>$ $90^{\circ}$, and a thin-cap fibroatheroma was defined as a LRP with minimal FCT of $<65 \mu \mathrm{m}$.

The signal-poor or heterogeneous region with a sharply delineated border detected in the plaque was identified as calcification. Spotty calcification was defined as calcification with an arc of $<90^{\circ}$. Macrophage accumulation was defined as signal-rich, distinct, or confluent punctate regions with heterogeneous backward shadows in the plaque. Microvessels presented as signal-poor voids sharply delineated with a diameter of $50-300 \mu \mathrm{m}$ visible in at least three cross-sections. Cholesterol crystals were identified by thin, linear, and signal-rich regions within the plaque. A layered plaque was defined as a plaque with heterogeneous signal-rich layered tissue of different optical signal intensity located close to the luminal surface that was clearly demarcated from the underlying tissue ${ }^{39)}$. The maximum thickness and area of the layered tissue was measured on the crosssectional view.

\section{Supplementary References}

37) Kang SJ, Mintz GS, Weisz G, Mehran R, Rabbani LE, Verheye S, Serruys PW, Xu K, Stone GW, Maehara A: Age-related effects of smoking on coronary artery disease assessed by gray scale and virtual histology intravascular ultrasound. Am J Cardiol, 2015; 115: 1056-1062

38) Inker LA, Astor BC, Fox CH, Isakova T, Lash JP, Peralta CA, Kurella Tamura M, Feldman HI: KDOQI US commentary on the 2012 KDIGO clinical practice guideline for the evaluation and management of CKD. Am J Kidney Dis, 2014; 63: 713-735

39) Shimokado A, Matsuo Y, Kubo T, Nishiguchi T, Taruya A, Teraguchi I, Shiono Y, Orii M, Tanimoto T, Yamano T, Ino Y, Hozumi T, Tanaka A, Muragaki Y, Akasaka T: In vivo optical coherence tomography imaging and histopathology of healed coronary plaques. Atherosclerosis, 2018; 275: 35-42 


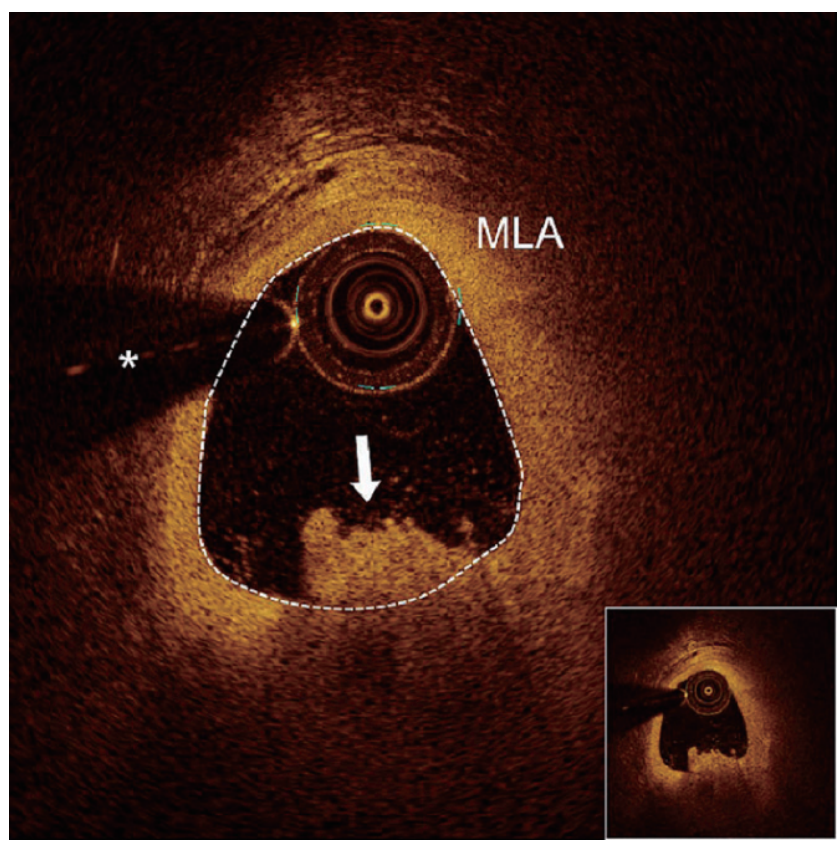

Supplementary Fig. 1. Measurement of minimal lumen area The figure shows an optical coherence tomography representative image of plaque erosion. The arrow points intracoronary thrombus presented on the surface of an atheroma. There is no evidence of intimal disruption. The MLA of this lesion is the area bounded by the luminal border (white dotted line) including the thrombus area.

*represented guidewire artifact. MLA, minimal lumen area. 
Supplementary Table 1. Clinical and coronary angiographical features of all STEMI patients with OCT-erosion

\begin{tabular}{lc}
\hline Variables & Overall $(n=348)$ \\
\hline Clinical characteristics & \\
Age, years & $54.5 \pm 11.0$ \\
Male & $276(79.3)$ \\
Smoking status & \\
$\quad$ Never & $101(29.0)$ \\
$\quad$ Former & $27(7.8)$ \\
$\quad$ Current & $220(63.2)$ \\
Diabetes mellitus & $52(14.9)$ \\
Hypertension & $124(35.6)$ \\
Dyslipidemia & $166(47.7)$ \\
CKD & $20(5.7)$ \\
Laboratory test & \\
TC, mg/dL & $178.0 \pm 42.7$ \\
TG, mg/dL & $136.8 \pm 78.1$ \\
LDL-C, mg/dL & $112.9 \pm 39.7$ \\
HDL-C, mg/dL & $50.3 \pm 11.3$ \\
cTnI, $\mu$ g/L & $1.6(0.3,10.2)$ \\
CK-MB, U/L & $14.7(2.0,87.1)$ \\
hs-CRP, mg/L & $6.5 \pm 5.0$ \\
pro-BNP, pg/ml & $302.0(69.0,1257.5)$ \\
STEMI onset to OCT imaging time, min & $300.0(200.0,501.5)$ \\
Coronary angiographic findings & \\
Culprit vessel & \\
LAD & \\
LCX & $217(62.4)$ \\
RCA & $28(8.0)$ \\
Segment & $103(29.6)$ \\
$\quad$ Proximal & \\
Mid & $159(45.7)$ \\
Distal & $132(37.9)$ \\
Lesion length, mm & $57(16.4)$ \\
RLD, mm & $18.2 \pm 9.0$ \\
MLD, mm & $3.1 \pm 0.5$ \\
DS, \% & $1.1 \pm 0.5$ \\
Initial TIMI flow 0-1 & $63.3 \pm 14.2$ \\
Multivessel disease & $226(64.9)$ \\
Thrombolysis & $116(33.3)$ \\
Thrombus aspiration & $19(5.5)$ \\
\hline V & $283(81.3)$ \\
\hline
\end{tabular}

Values expressed as $n(\%)$, mean \pm SD, or median (25th-75th percentiles).

A $p$-value $<0.05$ (A vs. B vs. C) or $p$-value $<0.017$ (two-group comparison) was considered statistically significant.

CKD, chronic kidney disease; CK-MB, creatine kinase-MB; cTnI, cardiac troponin I; DS, diameter stenosis; HDL-C, high-density lipoprotein cholesterol; hs-CRP, high-sensitive C-reactive protein; LAD, left anterior descending artery; LCX, left circumflex artery; LDL-C, low-density lipoprotein cholesterol; MLD, minimal lumen diameter; OCT, optical coherence tomography; pro-BNP, pro-type B natriuretic peptide; RCA, right coronary artery; RLD, reference lumen diameter; TC, total cholesterol; TG, triglyceride; TIMI, thrombolysis in myocardial infarction.
Supplementary Table 2. OCT findings of all OCT-erosions

\begin{tabular}{|c|c|}
\hline Variables & Overall $(n=348)$ \\
\hline Area stenosis, $\%$ & $67.4 \pm 17.4$ \\
\hline MLA, $\mathrm{mm}^{2}$ & $2.5 \pm 2.0$ \\
\hline $\mathrm{RLA}, \mathrm{mm}^{2}$ & $7.8 \pm 2.9$ \\
\hline Fibrous plaque & $174(50.0)$ \\
\hline Lipid plaque & $174(50.0)$ \\
\hline Lipid length, mm & $10.5 \pm 5.2$ \\
\hline Mean lipid arc, ${ }^{\circ}$ & $220.2 \pm 48.6$ \\
\hline Maximal lipid arc, ${ }^{\circ}$ & $301.4 \pm 63.6$ \\
\hline Minimal FCT, $\mu \mathrm{m}$ & $92.2 \pm 39.6$ \\
\hline LRP & $167(48.0)$ \\
\hline TCFA & $47(13.5)$ \\
\hline Macrophage & $190(54.6)$ \\
\hline Microvessels & $116(33.3)$ \\
\hline Cholesterol crystals & $71(20.4)$ \\
\hline Calcification & $105(30.2)$ \\
\hline Spotty calcification & $77(22.1)$ \\
\hline Nearby bifurcation & $218(62.6)$ \\
\hline Distance to bifurcation, $\mathrm{mm}$ & $2.4 \pm 1.5$ \\
\hline Layered plaque & $155(44.5)$ \\
\hline Layer thickness, $\mu \mathrm{m}$ & $570.0(440.0,770.0)$ \\
\hline Layer area, $\mathrm{mm}^{2}$ & $1.4(0.9,2.1)$ \\
\hline
\end{tabular}

Values expressed as $n(\%)$, mean $\pm \mathrm{SD}$, or median (25th-75th percentiles).

A $p$-value $<0.05$ (A vs. B vs. C) or $p$-value $<0.017$ (two-group comparison) was considered statistically significant.

FCT, fibrous cap thickness; LRP, lipid-rich plaque; MLA, minimal lumen area; OCT, optical coherence tomography; RLA, reference lumen area; TCFA, thin cap fibroatheroma. 


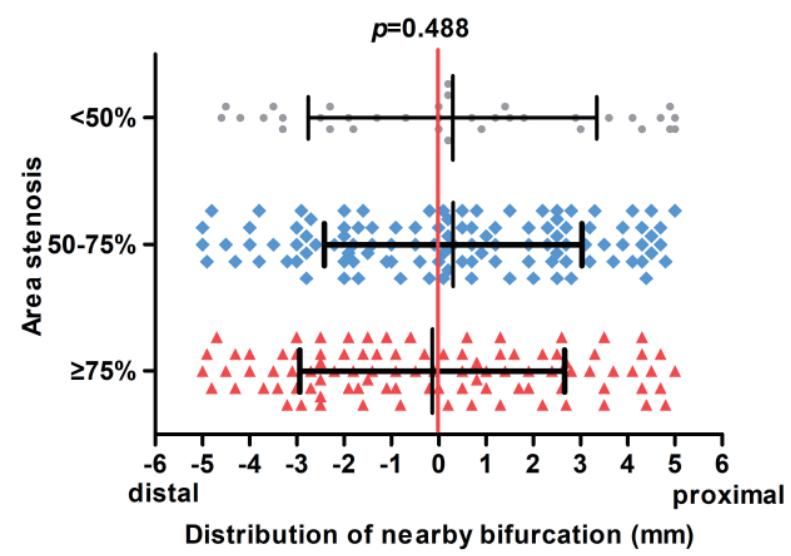

Supplementary Fig. 2. Distribution of nearby bifurcation to the site of minimal lumen area The red line represents the site of minimal lumen area (MLA). The distributions of nearby bifurcation to the site of MLA were similar among plaque erosions with different area stenosis $(p=0.488)$.

Supplementary Table 3. Univariable logistic regression analysis for OCT-erosion with noncritical stenosis

\begin{tabular}{|c|c|c|}
\hline \multirow[t]{2}{*}{ Variables } & \multicolumn{2}{|c|}{ Univariable analysis } \\
\hline & $P$ value & OR $(95 \% \mathrm{CI})$ \\
\hline Age $^{a}$ & 0.006 & $0.972(0.953-0.992)$ \\
\hline Male & 0.679 & $1.116(0.663-1.880)$ \\
\hline Current smoking & 0.113 & $1.427(0.920-2.213)$ \\
\hline Diabetes mellitus & 0.320 & $0.741(0.411-1.338)$ \\
\hline Hypertension & 0.027 & $0.607(0.390-0.944)$ \\
\hline Dyslipidemia & 0.105 & $1.423(0.929-2.179)$ \\
\hline $\mathrm{CKD}$ & 0.902 & $0.945(0.381-2.341)$ \\
\hline $\mathrm{TC}^{\mathrm{b}}$ & 0.348 & $1.002(0.997-1.008)$ \\
\hline $\mathrm{TG}^{\mathrm{b} .}$ & 0.292 & $1.002(0.999-1.004)$ \\
\hline $\mathrm{LDL}^{\mathrm{b}} \mathrm{C}^{\mathrm{f}}$ & 0.185 & $1.004(0.998-1.010)$ \\
\hline HDL-C ${ }^{b}$. & 0.985 & $1.000(0.981-1.019)$ \\
\hline LAD & 0.005 & $1.889(1.217-2.932)$ \\
\hline Multivessel disease & 0.033 & $0.613(0.391-0.961)$ \\
\hline Initial TIMI flow 0-1 & 0.698 & $1.092(0.701-1.701)$ \\
\hline Thrombolysis & 0.739 & $0.854(0.338-2.158)$ \\
\hline Thrombus aspiration & 0.470 & $1.221(0.711-2.096)$ \\
\hline Lesion length ${ }^{\mathrm{c}}$. & 0.364 & $0.984(0.951-1.018)$ \\
\hline RLA $^{\mathrm{d}}$. & 0.083 & $0.936(0.869-1.009)$ \\
\hline Fibrous plaque & $<0.001$ & $3.014(1.939-4.683)$ \\
\hline Macrophage & $<0.001$ & $0.442(0.285-0.684)$ \\
\hline Microvessels & 0.033 & $0.613(0.391-0.961)$ \\
\hline Cholesterol crystals & $<0.001$ & $0.364(0.212-0.624)$ \\
\hline Calcification & 0.032 & $0.604(0.381-0.958)$ \\
\hline Nearby bifurcation & 0.013 & $1.750(1.128-2.714)$ \\
\hline Layered plaque & 0.014 & $0.585(0.381-0.899)$ \\
\hline
\end{tabular}

a. OR for age was calculated for each 1-year increase; b. OR for TC, TG, LDL-C and HDL-C were calculated for each $1.0 \mathrm{mg} / \mathrm{dL}$ increase; c. OR for lesion length was calculated for each $1 \mathrm{~mm}$ increase; $\mathrm{d}$. OR for RLA was calculated for each $1 \mathrm{~mm}^{2}$ increase.

$\mathrm{CI}$, confidence interval; $\mathrm{CKD}$, chronic kidney disease; HDL-C, high-density lipoprotein cholesterol; LAD, left anterior descending artery; LDL-C, low-density lipoprotein cholesterol; LRP, lipid-rich plaque; OCT, optical coherence tomography; OR, odds ratio; RLA, reference lumen area; TC, total cholesterol; TG, triglyceride; TIMI, thrombolysis in myocardial infarction.

Advance Publication Journal of Atherosclerosis and Thrombosis 